|| ISSN(online): 2589-8698 || ISSN(print): 2589-868X || International Journal of Medical and Biomedical Studies Available Online at www.ijmbs.info

PubMed (National Library of Medicine ID: 101738825)

Index Copernicus Value 2018: 75.71

Original Research Article

Volume 3, Issue 10; October: 2019; Page No. 359-361

\title{
PREVALENCE OF SICK EUTHYROID SYNDROME IN NON-THYROIDAL ILLNESS
}

\section{Dr. Dattatray Hambhire}

Associate Professor Dept. of General Medicine Vedanta Institute of Medical Sciences Dahanu Palghar, Maharashtra.

Article Info: Received 08 October 2019; Accepted 29 October 2019

DOI: https://doi.org/10.32553/ijmbs.v3i10.777

Corresponding author: Dr. Dattatray Hambhire

Conflict of interest: No conflict of interest.

Abstract:

INTRODUCTION: Sick euthyroid syndrome is also known as low triiodothyronine (T3) syndrome or non-thyroidal illness syndrome which is characterized by alterations in the levels of thyroid hormones in the absence of any disorder related to thyroid gland or hypothalamic-hypophysial axis. Abnormal findings on thyroid functions tests which occur in the setting of a non thyroidal illness (NTI) without preexisting hypothalamic-pituitary and thyroid gland dysfunction. In the 1970s initially described low T3 (triiodothyronine) syndrome, known as the euthyroid sick syndrome or the nonthyroidal illness syndrome (NTIS). This can be representing especially in in critically ill patients, particularly those admitted to intensive care units. Although by definition these abnormalities are not related to intrinsic diseases of hypothalamus-pituitary-thyroid axis though rather represent imbalances in thyroid hormone production, metabolism, and action. As there is progress in illness gradual development of a more complex syndrome associated with low levels of T3 and thyroxine (T4). AIM: The main objective of this study is to study clinical profile sick euthyroid syndrome in Non-thyroidal Illness. MATERIAL AND METHODS: Total 60 patients were included in this study with the diagnosis of euthyroid syndrome with suggestive of Non-thyroidal IIIness. From all the patients detail history were recorded as data as well as all the necessary lab investigations were recorded as hemogram, renal function test, liver function test, ECG, Chest roentgenogram, and thyroid function status and serum cholrine esterase. RESULT: Total 60 patients were including in this study within the period of study with different age group. Patients with age group 20-30 years age group shows majority followed by age group 30-40 years age group as 33.3\% and 30\% respectively. Among the 60 patients only 15 patients were observed as sick Euthyroid. Out of 15 patients with sick Euthyroid 60\% showed Low T3 alone and 40\% shows changes in T3, T4 \& TSH Levels. CONCLUSION: Non-thyroidal illness syndrome is common among male in comparisons to female with the middle ages. Since the mechanism of sick euthyroid syndrome is similar to sick euthyroid syndrome in other critical care illnesses. Therefore more and more studies should be done for the better evaluation of the prognostic value of NTIS in critically ill. Thyroid functions should be assessed routinely in patients for prevent of Non-thyroidal illness syndrome.

KEYWORDS: sick euthyroid syndrome, Non-thyroidal IIIness, Thyroid

\section{Introduction:}

Sick euthyroid syndrome is also known as low triiodothyronine (T3) syndrome or non-thyroidal illness syndrome which is characterized by alterations in the levels of thyroid hormones in the absence of any disorder related to thyroid gland or hypothalamic-hypophysial axisi, ii. Abnormal findings on thyroid functions tests which occur in the setting of a non thyroidal illness (NTI) without preexisting hypothalamic-pituitary and thyroid gland dysfunction ${ }^{\text {iii }},{ }^{\text {iv }} \&^{v}$.

Most common thyroid function abnormalities in populations were found as a decreased level of serum total triiodothyronine (T3) with acute illness. Within 2 hours after the onset of severe physical stress that can be detected. Altered thyroid hormone levels can be found in acute and chronic medical illnesses, starvation, surgery, trauma, bone marrow transplantation, myocardial infarction and can be seen in any severe systemic illness ${ }^{\text {vi vii }}$.

In the 1970s initially described low T3 (triiodothyronine) syndrome, known as the euthyroid sick syndrome or the nonthyroidal illness syndrome (NTIS). This can be representing especially in in critically ill patients, particularly those admitted to intensive care units. Although by definition these abnormalities are not related to intrinsic diseases of hypothalamus-pituitary-thyroid axis though rather represent imbalances in thyroid hormone production, metabolism, and action. As there is progress in illness gradual development of a more complex syndrome associated with low levels of T3 and thyroxine (T4 
)$^{\text {viii ix }}$. More extreme changes in hormone pattern poorer the prognosis ${ }^{x}$. In cases of acute organophosphate poisoning also been seen in Sick euthyroid syndrome ${ }^{\mathrm{xi}}$.

In several physiological processes as normal growth development and metabolism Thyroid hormones are important and some imbalance in their levels could lead to a wide range of clinical conditions ${ }^{\mathrm{xii}}$.

The main objective of this study is to study clinical profile sick euthyroid syndrome in Non-thyroidal Illness.

\section{MATERIAL AND METHODS:}

This is a prospective study which is done in the period of one years and carried out at Vedanta Institute of Medical Sciences Dahanu Palghar, Maharashtra., in department of medicine. Total 60 patients were included in this study with the diagnosis of euthyroid syndrome with suggestive of Non-thyroidal Illness. From all the patients detail destroy were recorded as data as well as all the necessary lab investigations were recorded as hemogram, renal function test, liver function test, ECG, Chest roentgenogram, and thyroid function status and serum cholrine esterase.

\section{RESULT:}

Total 60 patients were including in this study within the period of study with different age group. Patients with age group 20-30 years age group shows majority followed by age group 30-40 years age group as $33.3 \%$ and $30 \%$ respectively as shown in table below.

Table 1: showing the no of patients according to age group in years.

\begin{tabular}{|c|c|c|}
\hline Age (Years) & numbers & Percentage (\%) \\
\hline $10-20$ & 12 & 20 \\
\hline $20-30$ & 20 & 33.3 \\
\hline $30-40$ & 18 & 30 \\
\hline $40-50$ & 7 & 11.7 \\
\hline $50-60$ & 3 & 5 \\
\hline Total & 60 & 100 \\
\hline \multicolumn{3}{|c|}{$\begin{array}{l}\text { Out of } 60 \text { patients males patients shows more } \\
\text { percentage of illness in comparing to female as } \\
\text { shown in table below. }\end{array}$} \\
\hline \multicolumn{3}{|c|}{ Table 2: showing no of patients according to gender. } \\
\hline Gender & Number & Percentage (\%) \\
\hline Male & 37 & 61.7 \\
\hline Female & 23 & 38.3 \\
\hline Total & 60 & 100.0 \\
\hline
\end{tabular}

Among the 60 patients only 15 patients were observed as sick Euthyroid as shown in table below.

Table 3: showing magnitude of sick euthyroid

\begin{tabular}{|c|c|c|}
\hline & Number & Percentage (\%) \\
\hline Normal Thyroid & 45 & 75 \\
\hline Sick Euthyroid & 15 & 25 \\
\hline Total & 60 & 100 \\
\hline \multicolumn{3}{|c|}{$\begin{array}{l}\text { Out of } 15 \text { patients with sick Euthyroid } 60 \% \text { showed } \\
\text { Low T3 alone and } 40 \% \text { shows changes in T3, T4 \& TSH } \\
\text { Levels as shown in table below. }\end{array}$} \\
\hline \multicolumn{3}{|c|}{ Table 4: showing spectrum of sick euthyorid } \\
\hline Spectrum & Number & Percentage (\%) \\
\hline Low T3 Alone & 9 & 60 \\
\hline Low T3, T4 Low TSH & 6 & 40 \\
\hline Total & 15 & 100 \\
\hline
\end{tabular}

DISCUSSION:

According to WHO studied reported as about 3 million cases of Non-thyroidal Illness and 40,000 deaths annually and majority were under the age group of thirty ${ }^{\text {xiii }}$. In this study showed that there was no influence on thyroid hormone alteration in NTI due to age which is similar to other studied done by Burrows AW et $a^{\text {xiv }}$. There are many studies which also reported high prevalence of SES in age between $20-30$ years subjects undergoing surgery ${ }^{\mathrm{xv}}$. From earlier studies report suggested that age are not influences in these alterations ${ }^{\mathrm{xvi}}$. Ames RG et.al of turkey studied showed as the mean age group of Non-thyroidal Illness was $30 \pm 15$ years ${ }^{\text {xvii }}$. In India the most common age group to be affected was 20-30 years $(36.6 \%)$ which is similar to this study ${ }^{13}$. In this study male (61.7\%) were more in compared to female (38.3\%) which is also similar to many studied as Malik et $\mathrm{a}^{\mathrm{x} \text { viii }}$ and $\mathrm{K}$. Raghavan et $\mathrm{al}^{\mathrm{xix}}$. In this study out of 60 patients' 15 (25\%) patients was showed incidence of sick euthyroid which is similar to the study of Guven et al in Turkey ${ }^{\mathrm{xx}}$. Although there was only 15 patients were sick euthyroid and among these 15 patients $9(60 \%)$ had low free T3 alone and 6(40\%) had low T3,T4 and TSH which is also similar to the study of Guven et al ${ }^{20}$ in Turkey showed as 2 had low fT3,2 had fT4 and 3 had low TSH. Although in this study mean T3 was significantly low in patients with acute Non-thyroidal Illness than with those with acute or chronic NTI. Hormone profile has been by now declared as a consistent feature of SES as many other studies shows ${ }^{x x i},{ }^{x x i i} \&^{x x i i i}$. 


\section{CONCLUSION:}

Non-thyroidal illness syndrome is common among male in comparisons to female with the middle ages. This study showed sick euthyroid syndrome in Nonthyroidal Illness is more prevalence in age of 20-30 years of age group in which males are more common. Since the mechanism of sick euthyroid syndrome is similar to sick euthyroid syndrome in other critical care illnesses. Therefore more and more studies should be done for the better evaluation of the prognostic value of NTIS in critically ill. Thyroid functions should be assessed routinely in patients for prevent of Non-thyroidal illness syndrome.

\section{REFERENCES:}

1. Wartofsky L, Burman KD. Alteration in thyroid function in patients with systemic illness: The "euthyroid sick syndrome". Endocr Rev 1982;3:164-217.

2. Marks SD. Nonthyroidal illness syndrome in children. Endocrine 2009;36:355-367. Epub 2009 Sep 25

3. Chopra I. Thyroid function in non-thyroid illnesses. Ann In-tern Med 1983; 98: 946-957.

4. Sypniewski E. Comparative pharmacology of the thyroid hormones. Ann Thorac Surg. 1993; 56 (suppl 1): S2-S8.

5. Docter $R$, Krenning $E P$, deJong $M$, et al. The sick euthyroid syndrome: chranges in thyroid hormone serum parameters and hormone metabolism. Clin Endocrinol 1993; 39: 499-518.

6. Chopra IJ: Clinical review 86: euthyroid sick syndrome: is it a misnomer? J Clin Endocrinol Metab 1997; 82:329-334

7. Michalaki $M$, Vagenakis AG, Makri $M$, et al: Dissociation of the early decline in serum $T(3)$ concentration and serum IL-6 rise and TNF- Ipha in nonthyroidal illness syndrome induced by abdominal surgery. J Clin Endocrinol Metab 2001; 86:4198-4205

8. Wong TK, Hershman JM: Changes in thyroid function in nonthyroidal illness. Trends Endocrinol Metab 1992; 3:8-12

9. Chopra IJ: Nonthyroidal illness syndrome or euthyroid sick syndrome? Endocrine Practice 1996; 2:45-52

10. Hamilton M. Prevalence and clinical implications of abnormal thyroid hormone metabolism in advanced heart failure. Ann Thorac Surg 1993; 56(suppl1): S48S53.

11. Human \& Experimental Toxicology, Vol.18 No. 10, 598601 (1999)

12. Fliers E, Bianco AC, Langouche L, Boelen A (2015) Thyroid function in critically ill patients. Lancet Diabetes Endocrinol 3: 816-825.

13. Palimar Vikram, Arun $M$, aralaya $K M$, Singh Bhoopendra, et.al (2005) Spectrum of Organophoshorous Poisoning in Manipal. Vol.5, No.2,
14. Burrows AW, Cooper E, Shakespeare RA. Low serum T3 in elderly sick; protein binding, thyroid and pituitary responsiveness and reverse T3 in elderly sick; protein binding, thyroid and pituitary responsiveness and reverse T3 concentrations. Clin Endocrinol 1977;7:289300.

15. Girvent M, Maestro S, Hernandez R, Carajol I, Mome J, Sancho JJ, Gubeen JM, Sitges-Serra A. Euthyroid sick syndrome, associated endocrine abnormalities in elderly undergoing operation. Surgery 1998;123:5607.

16. Shimamoto $Y$, Schimamoto $H$, Nakamora $H$. Factors influencing serum free T3 and free T4 in elderly euthyroid subjects. Japanese J Geriatrics Nippon Routh Igakkai Zashi 1989;26:401-6.

17. Ames RG,et.al.(1995),Neurological sequeale of organophosphrous poisoning,Arch Environ Health, 50:440-444.

18. Malik, G.M. (1998), Organophosphorus Poisoning in the Kashmir Valley, 1994 to 1997, NEJM, Vol. 338:1078-1079, No.15.

19. S. Shivakumar, K.Raghavan, et.al (2006) Organophosphorous poisoning : A Study of effectiveness of therapy with oximes, JAPI 54. 250-51.

20. Guven M, Sungue M, Eser B, Sari, I, Altuntas F. (2004), The effects of fresh frozen plasma on cholinesterase levels and outcomes in patients with organophosphate poisoning, J Toxicol Clin Toxicol; 42(5): 617 -23.

21. Carter JN, Eastman CJ, Corcoran JM, Lazarus L. Effect of severe chronic illness on thyroid function. Lancet 1974;2:971- 4.

22. Burger $A$, Dinichert $D$, Nicod P. Effect of amiodarone on serum triiodothyronine, reverse triiodothyronine, thyroxine and thyrotropin. J Clin Investigation 1976;58:255-9.

23. Brent GA, Hershman GM, Braunstein GD. Patients with severe non-thyroidal illness and low serum thyroxine concentration. Am J Med 1986;81:463-6. 